\title{
Age and Growth of the Largemouth Bass Micropterus salmoides in Lakes Shorenji and Nishinoko, Central Japan
}

\author{
Taiga Yodo and Seishi Kimura \\ Fisheries Research Laboratory, Mie University, Wagu, Shima, Mie 517-07, Japan \\ (Received August 18, 1995)
}

\begin{abstract}
Age and growth of the largemouth bass Micropterus salmoides (Pisces: Centrarchidae) were estimated from otoliths taken from samples collected in Lakes Shorenji (Mie Prefecture) and Nishinoko (Shiga Prefecture), water bodies having different physical and biological environments, from October 1991 to March 1993. The otoliths of the fish had narrow opaque and wide transparent zones, with opaque foci. Ring marks (outer margin of opaque zones) were formed on the otoliths once a year from June to August and May to July in Lake Shorenji and Lake Nishinoko specimens, respectively. The number of ring marks indicated approximately the full age of the fish because the marks formed one or two months after the spawning period. The fish from Lake Nishinoko were significantly heavier than those from Lake Shorenji for the same length. The growth curves for length were calculated to be $S L_{n}$ $=341(1-\exp (-0.4977(n+0.0697)))\left(\right.$ Lake Shorenji) and $S L_{n}=362(1-\exp (-0.4576(n+0.0892)))$ (Lake Nishinoko). Lake Nishinoko largemouth bass grew somewhat more rapidly than those in Lake Shorenji.
\end{abstract}

Key words: Largemouth bass, otolith, age, growth

The largemouth bass Micropterus salmoides, first introduced to Japan from the USA in 1925 , is now widely distributed in Japanese inland waters. Although the effects of predation on and disturbance of the Japanese native freshwater fish fauna by this species are considered serious, little is known about the ecological characteristics of the latter in Japan. Age determinations of the species in Japan have been made from size distributions ${ }^{1-3)}$ and scale readings. ${ }^{4,5)}$ A growth analysis was reported by Yokogaw$a^{3)}$ based on scale readings. The objective of this study is to clarify the age and growth parameters of the largemouth bass in Japanese waters and to compare the growth rates of populations in two lakes characterized by different environmental conditions.

\section{Materials and Methods}

The materials used in this study were caught by lure fishing in Lake Shorenji $(N=541)$, Mie Prefecture, Japan (lat. $34^{\circ} 36^{\prime} \mathrm{N}$, long. $\left.136^{\circ} 7^{\prime} \mathrm{E}\right)$ and Lake Nishinoko $(N=442)$, Shiga Prefecture, Japan (lat. $35^{\circ} 9^{\prime} \mathrm{N}$, long. $136^{\circ} 6^{\prime} \mathrm{E}$ ), once to three times a month from October 1991 to March 1993. The former lake is a typical reservoir $\left(1.04 \mathrm{~km}^{2}\right)$ with deep, clear water, whereas Lake Nishinoko $\left(2.17 \mathrm{~km}^{2}\right)$ is a typical natural swamp with shallow, muddy water. Yearly water temperatures ranged from 6.0 to $28.0^{\circ} \mathrm{C}$ in Lake Shorenji and from 6.0 to $31.2^{\circ} \mathrm{C}$ in Lake Nishinoko. Monthly changes in water temperature in Lake Shorenji were more gradual than in Lake Nishinoko. Accordingly, Lake Shorenji was somewhat colder in May to August and warmer in September to February than Lake Nishinoko.

Just after capture, $50 \%$ buffered formalin was injected into the body cavity of the fish, which were then kept on ice. Total length $(T L)$ and standard length $(S L)$ were meas- ured to the nearest millimeter, body weight $(B W)$ to the nearest $0.1 \mathrm{gram}$, and stomach content weight $(S C W)$, gonad weight $(G W)$, and hepatic weight $(H W)$ to the nearest $0.01 \mathrm{gram}$, in the laboratory. Somatic weight $(S W)$ was determined as follows: $S W=B W-$ $(S C W+G W+H W)$. Specimens ranged from 113 to 378 $\mathrm{mm} S L$ and 32.7 to $1534.3 \mathrm{~g} B W$ in Lake Shorenji, and from 98 to $430 \mathrm{~mm} S L$ and 24.9 to $2163.1 \mathrm{~g} B W$ in Lake Nishinoko.

The sagittal otoliths were removed from both sides of the head, cleaned in water and preserved dry in envelopes. The outer surfaces of otoliths soaked in xylene were examined at $10 \times$ or $20 \times$ magnifications using a dissecting microscope under translucent or reflection light. The ring marks (outer margin of opaque zones) on the otoliths were

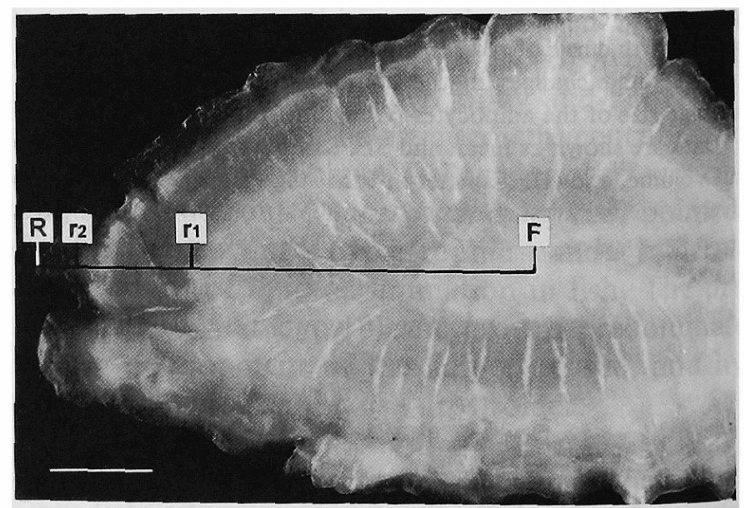

Fig. 1. Outer surface of the right sagittal otolith of a largemouth bass ( $251 \mathrm{~mm} \mathrm{SL}$ ) caught on 27 June 1992 in Lake Nishinoko.

F, focus; R, otolith radius; $r_{1}-r_{2}$, first and second ring radii (outer margins of opaque zones). 
counted, and the otolith radius $(R)$ and ring radii $\left(r_{n}\right)$ were measured from the focus to the posterior margin (Fig. 1), owing to the anterior portion of the otoliths often being abnormally shaped and/or having dense opacity. The otoliths were measured with an ocular micrometer to the nearest $0.01 \mathrm{~mm}$. In Lake Shorenji specimens, there were fewer countable otoliths on the left side (489 on the left, 498 on the right), whereas in Lake Nishinoko specimens, countable left and right otoliths were nearly equal (424 on the left, 423 on the right). Consequently, the right otoliths were usually used for the growth analyses, the left ones being used only if the former were unsuitable. For statistical tests, "Analysis of Variance (ANOVA)" and "Analysis of Covariance (ANCOVA)", were used. $\left.{ }^{6,7}\right)$

\section{Results}

\section{Otolith Morphology}

A sagittal otolith of the largemouth bass is shown in Fig. 1, the opaque focus being ringed in turn by a wide translucent and narrow opaque band. Ring marks were more distinct in specimens from Lake Nishinoko than in those from Lake Shorenji, some $15.7 \%$ of those in the latter not being readable under reflected light. Irregularly shaped otoliths also occurred more often in the fish from Lake Shorenji (10.2\%) than from Lake Nishinoko (8.2\%). Additionally, a few specimens from both lakes had polymarked otoliths described by Mio. ${ }^{8)}$ Those fish with abnormal otoliths were excluded from the growth analysis.

\section{Period of Ring Formation}

To estimate the periods of ring formation, monthly changes in the frequency of occurrence of specimens with opaque margins on their otoliths were examined (Fig. 2). Otoliths with opaque margins appeared from June to August (peaking in July, $41.5 \%$ ) in Lake Shorenji, and from May to July (peaking in June, 45.2\%) in Lake Nishinoko. This indicated that the ring marks on the otoliths were formed once a year and could be regarded as annual rings. Spawning occurred from April to June in Lake Shorenji and from April to May in Lake Nishinoko. Because ring marks were formed one or two months after the spawning period in each lake, the number of rings roughly indicated the full age of the fish.

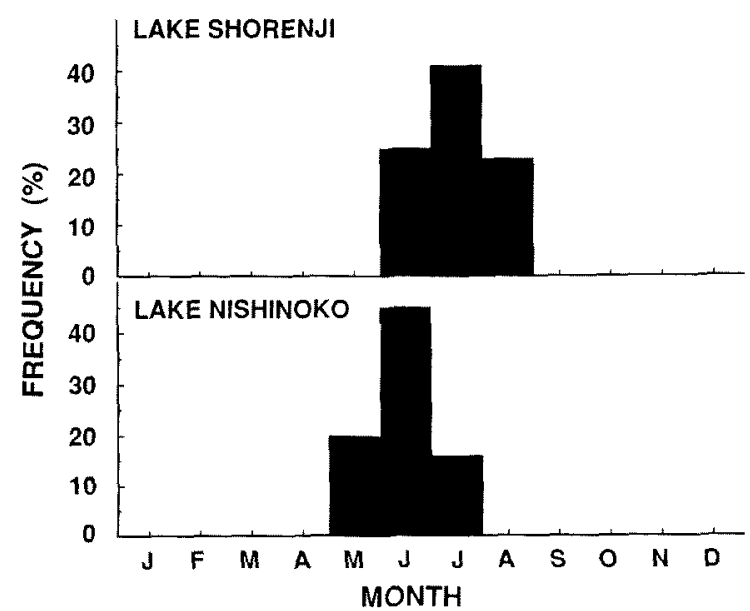

Fig. 2. Monthly changes in frequency of occurrence of the largemouth bass otoliths with opaque margins (black bars) in Lakes Shorenji and Nishinoko.

\section{Age Composition and Observed Length}

Because the spawning peaks of the largemouth bass in Lakes Shorenji and Nishinoko were determined as being in May and April, respectively (from field observations), the birth dates of the fish were taken as 1st May (Lake Shorenji) and 1st April (Lake Nishinoko) for analytical purposes. Age determination and standard lengths are shown in Table 1. The maximum ages determined were age 6 years in Lake Shorenji and age 7 years in Lake Nishinoko.

\section{TL-SL Relationships}

$T L-S L$ relationships in each lake were expressed by the following equations:

For Lake Shorenji:

$$
T L=1.222 S L+2.650(r=0.995) \text {. }
$$

For Lake Nishinoko:

$$
T L=1.196 S L+7.957(r=0.994) \text {. }
$$

Significant differences in the above relationships occurred between the two lakes at the 1\% level (ANCOVA).

\section{SL-BW and SL-SW Relationships}

$S L-B W$ and $S L-S W$ relationships were expressed by the

\begin{tabular}{|c|c|c|c|c|c|c|c|c|c|c|}
\hline \multirow{2}{*}{$\begin{array}{c}\text { Age } \\
\text { (years) }\end{array}$} & \multicolumn{5}{|c|}{ Lake Shorenji } & \multicolumn{5}{|c|}{ Lake Nishinoko } \\
\hline & Male & Female & Total & Standard length & Mean (S.D.) & Male & Female & Total & Standard length & Mean (S.D.) \\
\hline 0 & 0 & 0 & 0 & & & 7 & 8 & 15 & $98-156$ & $137(16)$ \\
\hline 1 & 33 & 35 & 68 & $113-251$ & $185(30)$ & 124 & 145 & 269 & $118-264$ & $191(30)$ \\
\hline 2 & 74 & 59 & 133 & $202-291$ & $257(17)$ & 45 & 54 & 99 & $175-308$ & $248(27)$ \\
\hline 3 & 92 & 75 & 167 & $230-360$ & $279(21)$ & 7 & 5 & 12 & $226-330$ & $285(30)$ \\
\hline 4 & 47 & 57 & 104 & $244-370$ & $298(27)$ & 8 & 16 & 24 & $242-388$ & $332(31)$ \\
\hline 5 & 21 & 8 & 29 & $240-364$ & $316(25)$ & 5 & 10 & 15 & $283-400$ & $344(34)$ \\
\hline 6 & 3 & 6 & 9 & $274-376$ & $343(36)$ & 2 & 1 & 3 & $349-370$ & $357(11)$ \\
\hline 7 & 0 & 0 & 0 & & & 1 & 1 & 2 & $372-430$ & $401(41)$ \\
\hline Unknown & 20 & 11 & 31 & $245-378$ & $294(28)$ & 0 & 4 & 4 & $217-380$ & $300(78)$ \\
\hline Total & 291 & 250 & 541 & $113-378$ & $269(44)$ & 198 & 244 & 442 & $98-430$ & $220(59)$ \\
\hline
\end{tabular}

Table 1. Number of specimens and standard length ranges in each age class of largemouth bass in Lakes Shorenji and Nishinoko 
following equations:

For Lake Shorenji:

$$
\begin{aligned}
& \log _{10} B W=3.038 \log _{10} S L-4.705(r=0.985) \\
& \log _{10} S W=2.999 \log _{10} S L-4.620(r=0.987) .
\end{aligned}
$$

For Lake Nishinoko:

$$
\begin{aligned}
& \log _{10} B W=2.976 \log _{10} S L-4.523(r=0.994) \\
& \log _{10} S W=2.961 \log _{10} S L-4.499(r=0.992) .
\end{aligned}
$$

Significant differences in $S L-B W$ and $S L-S W$ relationships occurred between the two lakes at the 1\% level (ANCOVA). Specimens from Lake Nishinoko were heavier than those of similar standard length from Lake Shorenji.

\section{R-SL Relationships and Back-Calculated Standard Lengths}

No significant difference in $R-S L$ relationships occurred between the sexes from either lake at the 5\% level (ANCOVA). The $R-S L$ relationships of specimens from each lake are shown in Fig. 3, being expressed by the following equations:

For Lake Shorenji:

$R=0.0111 S L+1.17(S L=74.4 R-40.7 ; r=0.909)$.

For Lake Nishinoko:

$$
R=0.0117 S L+1.21(S L=75.0 R-63.7 ; r=0.937) \text {. }
$$

Figure 3 indicates the degree of variation in otolith radius in specimens of the same length. It was considered that if the ring radii also varied with the otolith radius, then the former might exhibit similar individual variability. In order to minimize any complication introduced by ring radius variability, each ring radius was standardized by the following equation, 9 )

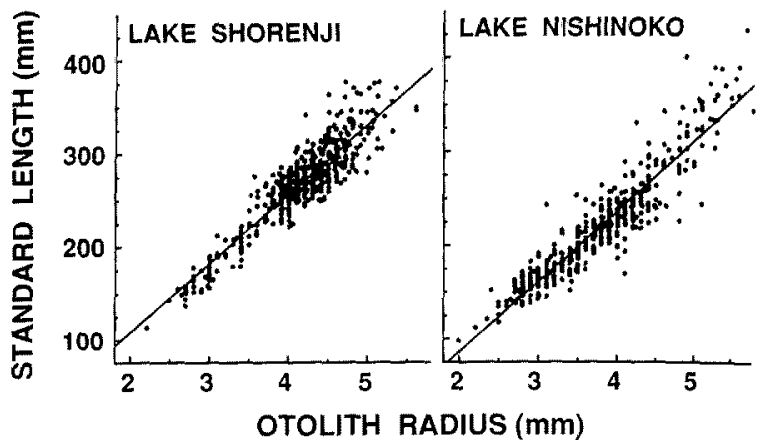

Fig. 3. Relationship between otolith radius and standard length of the largemouth bass collected in Lakes Shorenji and Nishinoko.

$$
\hat{r}_{n}=(\hat{R} / R) r_{n},
$$

where $R=$ measured otolith radius, $\hat{R}=$ standard otolith radius computed from the standard length by applying equation (7) or (8), $r_{n}=$ measured ring radius, and $\hat{r}_{n}=$ standard ring radius.

The standard length of each specimen at the time of each ring formation was back-calculated from each standard ring radius by applying equation (7) or (8). Mean back-calculated lengths in each ring group are shown in Tables 2 and 3 . No significant difference between the sexes in either lake occurred in their mean lengths at the time of each ring formation, at the 5\% level (ANOVA). The weighted mean standard lengths at the first to 6 th ring formation were used for the growth analysis. The mean

\begin{tabular}{|c|c|c|c|c|c|c|c|}
\hline Ring Group & Number of fish & $1 /$ & $l_{2}$ & $l_{3}$ & $l_{4}$ & $J_{5}$ & $l_{5}$ \\
\hline 1 & 85 & $160(14.1)$ & & & & & \\
\hline 2 & 161 & $146(18.6)$ & $229(14.0)$ & & & & \\
\hline 4 & 63 & $152(19.1)$ & $232(15.2)$ & $271(17.2)$ & $293(20.1)$ & & \\
\hline 5 & 7 & $154(27.4)$ & $236(14.8)$ & $277(14.7)$ & $302(17.7)$ & $320(19.0)$ & \\
\hline 6 & 4 & $160(8.8)$ & $230(20.7)$ & $277(27.9)$ & $298(32.9)$ & $313(6.2)$ & $326(40.2)$ \\
\hline
\end{tabular}
length at the 7th ring formation was excluded from the analysis because of its low reliability due to too few samples with a wide range of length.

Table 2. Mean back-calculated standard lengths ( $\mathrm{mm}$ ) and standard deviations (in parentheses) at the time of each otolith ring formation in largemouth bass in Lake Shorenji

Table 3. Mean back-calculated standard lengths ( $\mathrm{mm}$ ) and standard deviations (in parentheses) at the time of each otolith ring formation in largemouth bass in Lake Nishinoko

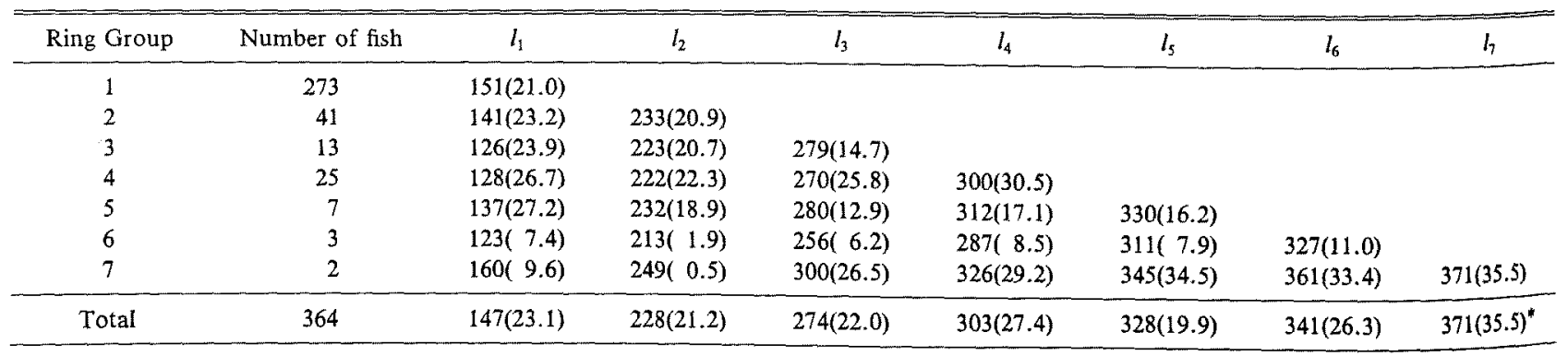

* Excluding from growth analysis. 


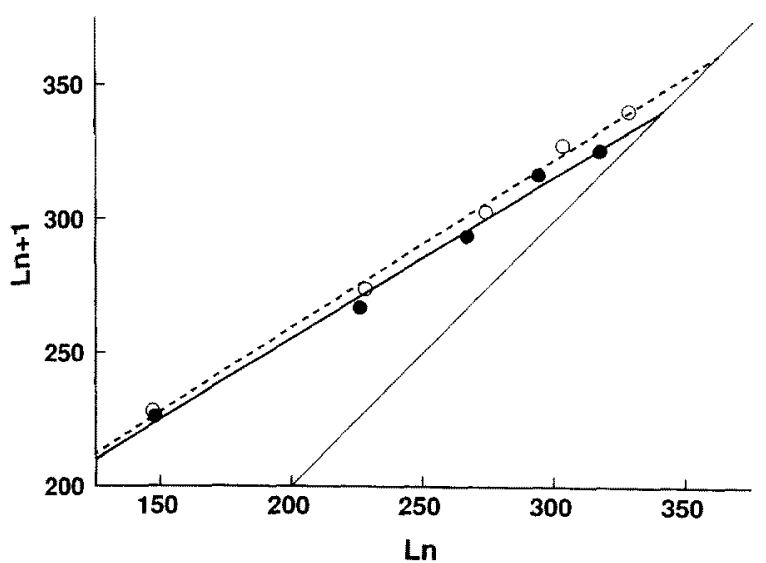

Fig. 4. Walford's growth transformation of standard lengths.

Solid circles with solid line indicate the Lake Shorenji largemouth bass population; open circles with dashed line indicate the Lake Nishinoko population.

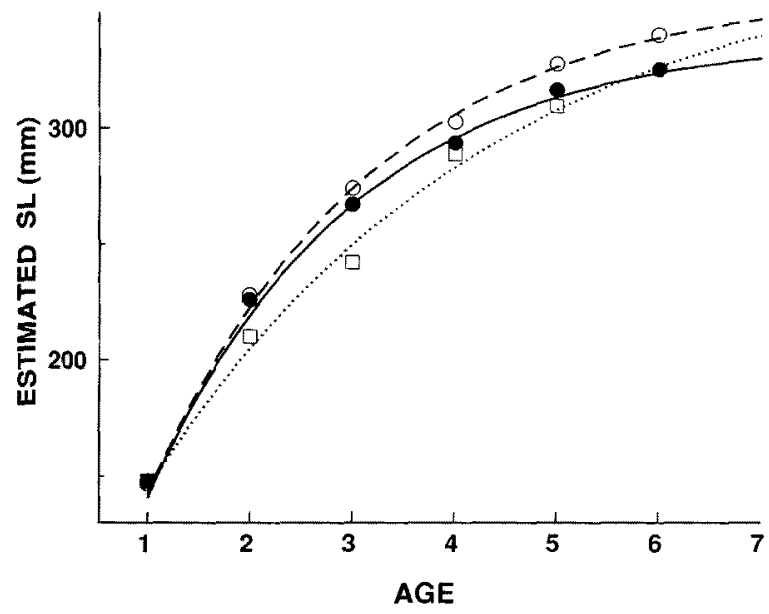

Fig. 5. Von Bertalanffy's length growth curves for largemouth bass.

Solid circles with solid curve indicate the Lake Shorenji population; open circles with dashed curve indicate the Lake Nishinoko population; open squares with dotted curve indicate the Manno Pond population (after Yokogawa). ${ }^{3 !}$

\section{Growth Equations}

Walford's growth transformations of mean back-calculated lengths are shown in Fig. 4, the plots almost conforming to straight lines. Accordingly, the growth curves could be fitted to von Bertalanffy's model, with both length and weight in each lake described as follows (Fig. 5):

For Lake Shorenji:

$$
\begin{aligned}
& S L_{n}=341(1-\exp (-0.4977(n+0.0697))) \\
& B W_{n}=976.1(1-\exp (-0.4977(n+0.0697)))^{3.038} \\
& S W_{n}=945.6(1-\exp (-0.4977(n+0.0697)))^{2.999} .
\end{aligned}
$$

For Lake Nishinoko:

$$
S L_{n}=362(1-\exp (-0.4576(n+0.0892)))
$$

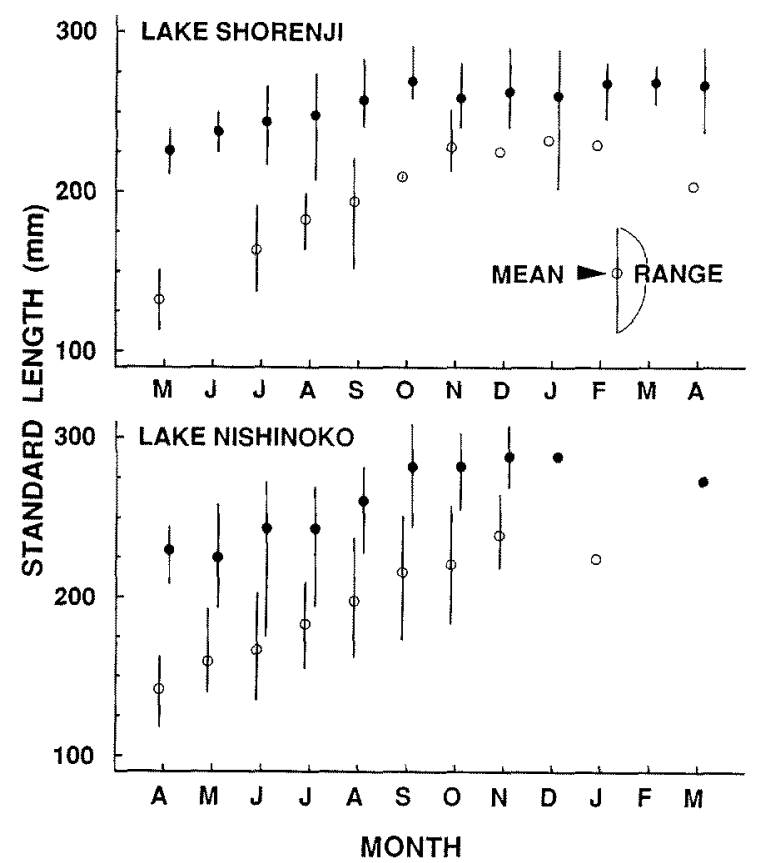

Fig. 6. Monthly changes in the observed standard lengths of 1 (open circles) and 2 (solid circles) year-old largemouth bass in Lakes Shorenji and Nishinoko.

$$
\begin{aligned}
& B W_{n}=1235.1(1-\exp (-0.4576(n+0.0892)))^{2.976} \\
& S W_{n}=1194.9(1-\exp (-0.4576(n+0.0892)))^{2.961},
\end{aligned}
$$

where $S L_{n}=$ standard length at the time of the $n$-th ring formation, $B W_{n}=$ body weight at the time of the $n$-th ring formation, and $S W_{n}=$ somatic weight at the time of the $n$-th ring formation.

\section{Growing Seasons}

Monthly changes in the observed standard lengths of 1and 2-year-old fishes in each lake are shown in Fig. 6. The fish in Lake Shorenji increased in length from May to November (1-year-old) or October (2-year-old), and those in Lake Nishinoko, from April to November. Therefore, the growing season of largemouth bass was estimated as being from May to November inclusive in Lake Shorenji, and from April to November inclusive in Lake Nishinoko.

\section{Discussion}

The differences in $S L-B W$ and $S L-S W$ relationships in largemouth bass between the two lakes may be attributable to differences in feeding conditions. Stomach-content analysis of the fish from Lakes Shorenji and Nishinoko* showed that those from the former lake fed on less amount of prey animals (main preys: a goby Rhinogobius sp., a prawn Macrobranchium nipponense, and a shrimp Palaemon paucidens) than those from the latter (a crayfish Procambarus clarkii and the prawn) through the year.

The asymptotic maximum standard lengths were estimated to be $341 \mathrm{~mm}$ (Lake Shorenji) and $362 \mathrm{~mm}$ (Lake

\footnotetext{
* T. Yodo: Comparative ecology of the largemouth bass in Lake Shorenji and Lake Nishinoko. M. S. thesis, Faculty of Bioresource, Mie University, Tsu. 1995. p. 34
} 
Nishinoko), whereas the observed maximum lengths were 376 and $430 \mathrm{~mm}$, respectively. There were somewhat large differences between the asymptotic and observed maximum lengths in both lakes. However, because the asymptotic maximum length represents the average maximum length of the population, and the mean back-calculated lengths at the 6th ring formation were $326 \mathrm{~mm}$ (Lake Shorenji) and $341 \mathrm{~mm}$ (Lake Nishinoko), the asymptotic maximum lengths obtained appeared reasonable.

Differences in growth rates between the two lakes were also tested. In Walford's growth transformation, these were not significant at the 5\% level (ANCOVA). Although the mean back-calculated lengths of 3-year-old fish from Lake Nishinoko were significantly greater than those from Lake Shorenji ( $1 \%$ level, ANOVA), the differences between the mean lengths of the other age groups in the two lakes were not significant ( $5 \%$ level, ANOVA). However, the mean lengths of 2-to 6-year-old fish and the asymptotic maximum lengths from Lake Nishinoko were apparentIy larger than those from Lake Shorenji, indicating that fish in Lake Nishinoko grew somewhat more rapidly than those in Lake Shorenji. Figure 6 indicates that the growing periods in both lakes were almost of the same length. Accordingly, the growth differences presented here are also attributed to differences in the feeding conditions in the two lakes.

Yokogawa ${ }^{3)}$ analyzed the growth of largemouth bass in Manno Pond (Kagawa Prefecture, Japan) from scale readings (Fig. 5). His back-calculated standard lengths (converted from $T L$ using his $T L-S L$ relationship ${ }^{10)}$ ) in 1- to 5 year-old fish were somewhat smaller than those given here. Comparing with age-size data from other Japanese lakes and ponds, the growths of largemouth bass from Lakes Shorenji and Nishinoko were almost the same as those from Lake Biwa (Shiga Prefecture) ${ }^{1)}$ and Hachiman Pond (Kagawa Prefecture), ${ }^{2,3)}$ but more rapid than those from Lake Ashinoko (Kanagawa Prefecture). ${ }^{4,5}$

Many reports on the growth of largemouth bass from American waters ${ }^{11-15)}$ showed wide variations in the growth rate depending on the locality. The growth rates obtained here were within the range of data from the USA.

Acknowledgments We would like to thank Dr. G. S. Hardy, Thames, New Zealand, for further assistance with English and critical comments. We also express our gratitude to Mr. N. Shibuya, for his great help in collecting and measuring the specimens.

\section{References}

1) O. Yamanaka: Seichô ni tsuite. Shôwa 60-62 nendo ookuti basu taisaku sôgô chôsa kenkyî hôkokusho [Growth. Report on the general research project for the largemouth bass in 1985-87]. Shigaken Suisanshikenjô Hôkoku, 40, 15-26 (1989) (in Japanese).

2) K. Yokogawa: Gairaigyo taisaku kentô jigyô [Examination project for introduced fishes], in "Heisei gannendo Kagawa-ken suisanshikenjô jigyô hôkoku", Kagawa Pref. Inst. Fish., Takamatsu, 1991, pp. 101-106 (in Japanese).

3) K. Yokogawa: Gairaigyo mondai taisaku kentô jigyô [Examination project for introduced fishes], in "Heisei 2 nendo Kagawa-ken suisanshikenjô jigyô hôkoku", Kagawa Pref. Inst. Fish., Takamatsu, 1992, pp. 69-86 (in Japanese).

4) T. Nishihara: Ashinoko ni okeru black bass (Micropterus salmoides (Lacepède)) no keitaiteki kenkyü to shokusei no keikô ni tsuite-I [Morphology and feeding habit of the black bass in Lake Ashinoko-1]. Kanagawa-ken Tansuigyo Zôshokujô Hôkoku, 9, 6178 (1972) (in Japanese).

5) T. Nishihara and T. Murayama: Ashinoko ni okeru saikin no black bass (ookuti basu (Micropterus salmoides (Lacepède))) ni tsuite-II [Recent situation of the black bass in Lake Ashinoko]. Kanagawaken Tansuigyo Zôshokujô Hôkoku, 10, 74-83 (1972) (in Japanese).

6) G. W. Snedecor and W. G. Cochran: Statistical methods. 6th ed. (Translated from English by M. Hatayama, C. Okuno, and Y. Tsumura), Iwanami, Tokyo, 1972, pp. 246-284 (in Japanese).

7) G. W. Snedecor and W. G. Cochran: Statistical methods. 6th ed. (Translated from English by M. Hatayama, C. Okuno, and Y. Tsumura), Iwanami, Tokyo, 1972, pp. 394-416 (in Japanese).

8) S. Mio: The poly-mark group in the age mark of the otolith. Bull. Seikai Reg. Fish. Res. Lab., 46, 21-32 (1974) (in Japanese).

9) S. Mio: Studies on population biology of coastal fishes in Kyushu-I: Biology of Sebastes inermis Cuvier et Valenciennes. Sci. Bull. Fac. Agr. Kyushu Univ., 18, 419-436 (1961) (in Japanese).

10) K. Yokogawa: Ki-inyûgyoshu no seitai haaku no kokoromi [Tentative study to understand the ecology of introduced fishes], in "Heisei gannendo gairaigyo taisaku kentô itaku jigyô hôkokusho", Fishery Agency, Tokyo, 1990, pp. 66-77 (in Japanese).

11) G. W. Bennett: The growth of the large mouthed black bass, Huro salmoides (Lacépède), in the waters of Wisconsin. Copeia, 1937, 104-118 (1937)

12) R. S. McCaig and J. W. Mullan: Growth of eight species of fishes in Quabbin Reservoir, Massachusetts, in relation to age of reservoir and introduction of smelt. Trans. Am. Fish. Soc., 89, 27-31 (1960).

13) J. F. Webb and W. C. Reeves: Age and Growth of Alabama spotted bass and northern largemouth bass, in "Black bass biology and management" (ed. by R. H. Stroud and H. Clepper), Sport Fishing Institute, Washington, D. C., 1975, pp. 204-215.

14) C. M. Smagula and I. R. Adelman: Growth in a natural population of largemouth bass, Micropterus salmoides Lacepede, as determined by physical measurements and $\left[{ }^{14} \mathrm{C}\right]-$ glycine uptake by scales. J. Fish. Biol., 22, 695-703 (1983).

15) M. R. Meador and W. E. Kelso: Growth of largemouth bass in lowsalinity environments. Trans. Am. Fish. Soc., 119, 545-552 (1990). 